

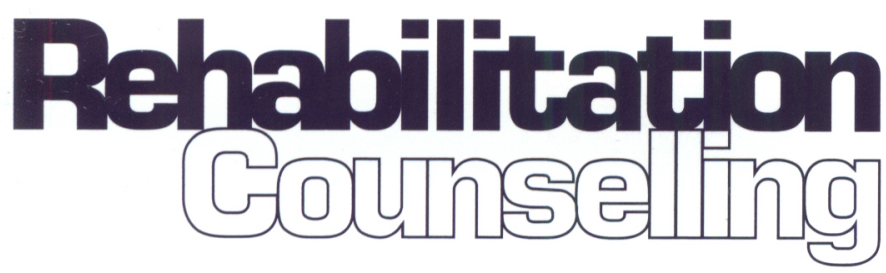

\section{Guidelines for Authors}

The Australian Journal of Rehabilitation Counselling (AJRC) is a peer-reviewed scientific publication in the multidisciplinary field of rehabilitation and disability. AJRC receives national and international submissions and topics include rehabilitation counselling, case management, rehabilitation education, rehabilitation administration, job placement, vocational assessment, psychosocial rehabilitation, independent living, transition planning, supported employment, industrial rehabilitation and disability management.

Only original scientific rehabilitation research and development papers (including pilot studies), selected reviews and special reports are accepted. AJRC welcomes submissions of graduate student research and submissions on new approaches and innovations in the field. AJRC does not publish letters to the editor or other submissions of a more journalistic style.

Guidelines for preparation and submission of manuscripts are given below. Intending contributors should submit their manuscript preferably as an e-mail attachment to:

The Editor, Ross Flett PhD

E-mail: R.A.Flett@massey.ac.nz

Postal address:

School of Psychology, Massey University

Private Bag 11-222

Palmerston North

New Zealand

A cover letter should accompany the manuscript as a separate e-mail attachment, which includes a return mail address and e-mail address, and state the following:

1. the name, credentials, affiliation, address, telephone number, fax number, and e-mail address of the corresponding author

2. that this manuscript is an original work that has not been submitted to nor published anywhere else

3. that all authors have read and approved the paper and have met the criteria for authorship as established by the International Committee of Medical Journals Editors (see http://www.icmje.org/index.html\#author)

4. that authors have read the discussion provided by the International Committee of Medical Journal editors on overlapping publications (see http://www.icmje.org/index.html\#over).

\section{Manuscript Preparation}

1. Authors should prepare manuscripts according to the Publication Manual of the American Psychological Association (5th ed., 2001). Spelling should conform to The Macquarie Dictionary (4th ed.)

2. Articles not prepared according to the guidelines of the Manual will not be reviewed.

3. All manuscripts must include an abstract containing a maximum of 120 words typed on a separate page.

4. Manuscripts would not normally exceed 20 doublespaced A4 typed pages inclusive of abstract, text, references, appendices, tables, and figures. However, longer manuscripts will be considered. Short reports (1200-1500 words) of empirical research are welcome.

\section{Manuscript Review}

1. The journal uses a blind review process in which the author's identity is anonymous to referees.

2. Unless otherwise indicated in the cover letter, the first author will be responsible for communication with the editor and editorial revisions of manuscripts.

3. Although feedback will usually be provided to authors, the editor reserves the right to reject a manuscript for publication without providing a rationale for the decision.

4. The final decision regarding acceptance of a manuscript will be made by the editor.

\section{Manuscripts Accepted for Publication}

1. Upon acceptance for publication, authors must provide the editor with a copy of their manuscript (via an e-mail attachment) and a final printed copy which is an exact match to the e-mailed version. The only acceptable word processing formats are Microsoft Word or RTF.

2. Accepted manuscripts become the sole property of the journal for copyright purposes. However, the author(s) remain responsible for any views expressed in a manuscript that is published. 

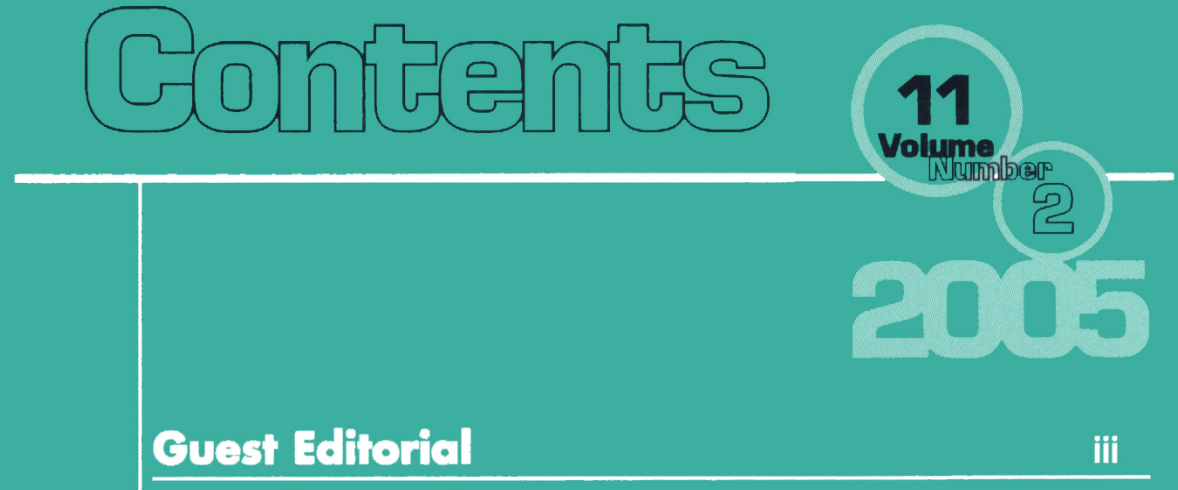

Trevor Hawkins, Guest Editor

\section{Articles}

Medication Adherence in New Zealand Older Adults:

Effects of an External Cognitive Support

June Greyvenstein, Nikolaos Kazantzis and Nancy A. Pachana

Predicting Return To Work After Workplace Injury:

A Review of Current Literature

Richard Hilion

Alleviating Distress Associated With Psychotic-Type

Disorders With a 10-Session, Manualised Combination

of CBT and ACT in New Zealand

Ruth Gillingham and Patrick L. Dulin

Testing an Adapted ICF Model: Aging, Vision

Impairment, Activity, Participation and Subjective

Dimensions of Functioning

Gretchen Ann Good

Hauora Tāne: Māori Men, Health Behaviours, and the Stages of Change Model

10 Paddison, Hemi Heta and Ross Flett 